\title{
From Kinetic study to thermal safety assessment: application to
}

\section{peroxyformic acid synthesis}

Sébastien Leveneura,b*, Martin Thönesa, Jean-Pierre Hébertc, Bechara Taouka, Tapio Salmib

a LSPC-Laboratoire de Sécurité des Procédés Chimiques, EA 4704, INSA Rouen, BP08, Avenue de I'Université, 76801 Saint-Etienne-du-Rouvray, France.Tel: +33 2329566 54; Fax: +33 2329566 52; E-mail: sebastien.leveneur@insa-rouen.fr

b Laboratory of Industrial Chemistry and Reaction Engineering, Process Chemistry Centre, Åbo Akademi University, Biskopsgatan 8, FI-20500 Åbo/Turku, Finland.

c CERTI SPEA, INSA Rouen, BP08, Avenue de I'Université, 76801 SaintEtienne-du-Rouvray, France.

ABSTRACT

This article proposes a kinetic and thermal study of the formic acid perhydrolysis in a semi-batch process at various hydrogen peroxide concentrations (5.32-8.21 $\mathrm{mol} / \mathrm{l})$, formic acid molar inlet flow rates $(0.04-0.22 \mathrm{~mol} / \mathrm{min})$, reaction temperatures $\left(30-60^{\circ} \mathrm{C}\right)$ and catalyst amount (0.0-10.6 grams). A cation exchange resin, i.e., Amberlite IR-120, was used as a catalyst. Synthesis and decomposition of peroxyformic acid were modeled by coupling the energy and mass balances, and a pseudo-homogeneous model for the reaction kinetics. A nonlinear regression method was used to estimate the kinetic parameters such 
as rate constant and thermal parameters such as reaction enthalpy. The knowledge of these parameters allows the determination of maximum temperature of the synthesis reaction (MTSR), the time to maximum rate under adiabatic condition (TMRad) and the criticality classification. These safety parameters are important to properly design the industrial reactor.

Keywords: Peroxycarboxylic acid, kinetics, mathematical modelling, safety calorimetry, semi-batch reactor. 


\section{INTRODUCTION}

Peroxycarboxylic acids are widely used in industry as detergent, bleaching and disinfecting agents. These chemicals are used as intermediates for the production of epoxidized vegetable oils [1-5], essentially peroxyacetic and peroxyformic acid can be produced in-situ.

Different synthesis methods can be used, such as oxidation of the parent aldehyde [6] or carboxylic acid [7]. However, perhydrolysis of the corresponding carboxylic acid by hydrogen peroxide [8] allows a greener way of the synthesis:

$$
\mathrm{RCOOH}+\mathrm{H}_{2} \mathrm{O}_{2} \rightleftarrows \mathrm{RCO}_{3} \mathrm{H}+\mathrm{H}_{2} \mathrm{O}
$$

The perhydrolysis is a reversible reaction and can be catalyzed by using acid species such as sulfuric acid or cation exchange resin [9]. This reaction is exothermic.

Pioneering research on peroxyformic acid synthesis has been made by D'Ans and Frey [10] in 1914. Recently, Rubio et al. [11] have proposed a mechanism of the peroxycarboxylic acid formation, demonstrating that the protonation of the carboxylic group is more favourable. De Filippis et al. [12] and Xiaoying Sun et al. [13] have made a kinetic study of peroxyformic acid synthesis by taking into account the dissociation of formic acid and the decomposition of peroxyformic acid. None of these authors have taken into account the energy balance for this reaction system. 
The goal of this paper was to propose a mathematical model including mass and energy balances to estimate kinetic and thermal parameters of peroxyformic acid synthesis. Experiments were carried out in a semi-batch calorimetric reactor. The last part of the work was dedicated to a preliminary safety assessment for the synthesis of peroxyformic acid from formic acid and hydrogen peroxide. 


\section{EXPERIMENTAL SECTION}

\subsection{Apparatus and experimental procedures}

Experiments were carried out in a $500 \mathrm{ml}$ jacketed glass reactor (Figure 1) equipped with pitched blade impeller and different temperature probes. The top of the reactor was insulated to diminish the heat losses due to evaporation of the reaction mixture. Water, circulating in the jacket, was used as heat transfer fluid. To avoid the accumulation of gas in case of peroxide decomposition, a reflux condenser was placed on top of the reactor. A calibration heater was in contact with the reaction mixture to determine the specific heat capacity and the heat transfer coefficient.

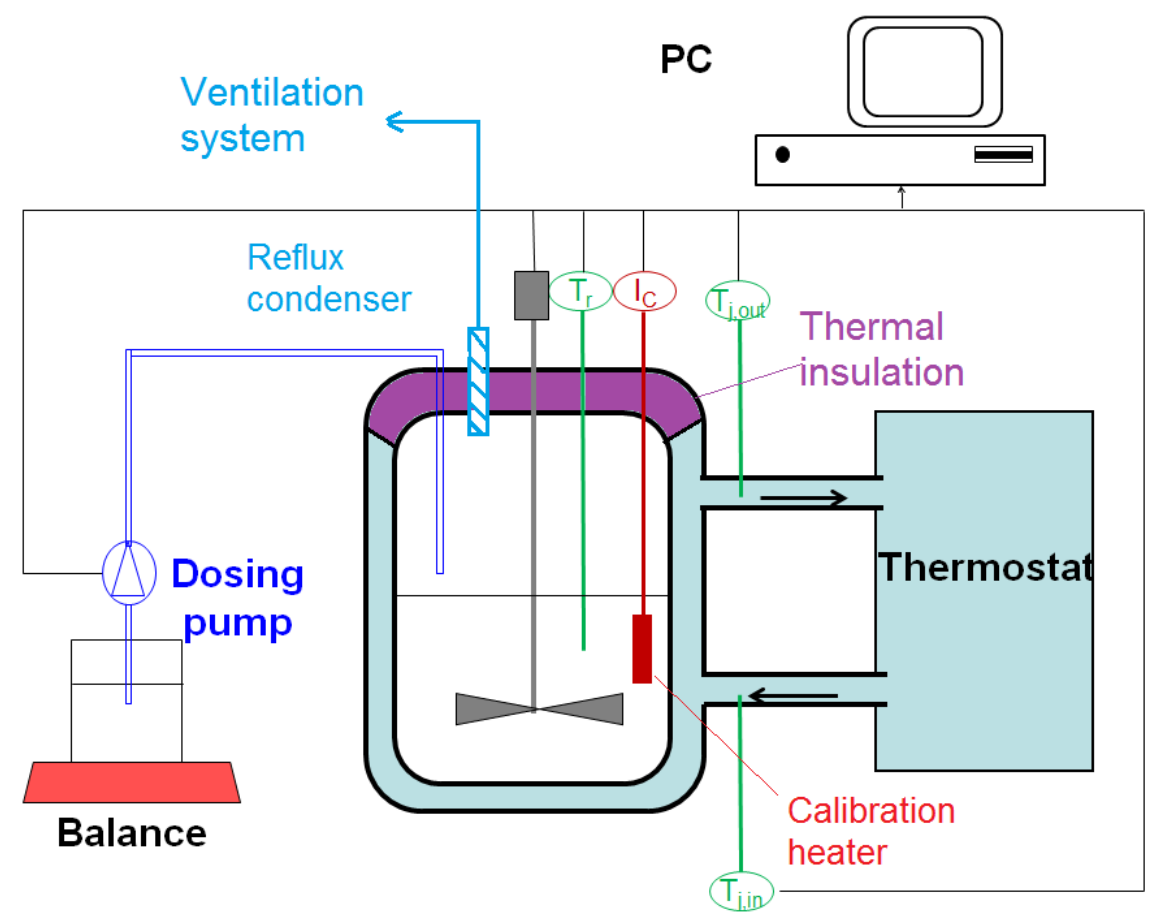

Figure 1. Schematic representation of the experimental setup. 
In a first step, water, hydrogen peroxide and Amberlite IR-120 were added together into the reactor. As the desired temperature was reached, a first calibration step, i.e., by Joule heating, was carried out to measure the specific heat capacity of the reaction mixture and global heat transfer coefficient through the jacket. Then, a preheated solution of formic acid was added through a dosing pump. A last calibration was made at the end of the reaction.

To prevent contamination induced by alkaline and metal components, which initiate the catalytic decomposition of peroxyformic acid and hydrogen peroxide, all parts of the reactor system being in contact with the reaction solution were washed with hydrochloric acid, followed by another washing, with a phosphatefree detergent solution.

The catalytst acidity due to the active site of the resin was expressed as $\left[-\mathrm{SO}_{3} \mathrm{H}\right]$, which corresponds to the number of Brønsted sites of the solid catalyst present per liter of reaction mixture. It was carried out on the basis of the cation exchange capacity by dry weight (meq/g). Amberlite IR-120 was used as a cation exchange resin, which capacity by dry weight is equal to $4.4 \mathrm{meq} / \mathrm{g}$ and was dried before at $90^{\circ} \mathrm{C}$ for $48 \mathrm{~h}$. 
Table 1 introduces the experimental matrix.

Table 1. Experimental matrix.

\begin{tabular}{|c|c|}
\hline Reaction temperature & $30-60^{\circ} \mathrm{C}$ \\
\hline Rotation speed & $100-300 \mathrm{rpm}$ \\
\hline$\dot{\mathrm{n}}_{\mathrm{FA}}$ & $0.04-0.22 \mathrm{~mol} / \mathrm{min}$ \\
\hline$\left[\mathrm{H}_{2} \mathrm{O}_{2}\right]_{\mathrm{O}}$ & $5.32-8.21 \mathrm{~mol} / \mathrm{l}$ \\
\hline$\left[\mathrm{H}_{2} \mathrm{O}\right]_{\mathrm{O}}$ & $45.38-49.05 \mathrm{~mol} / \mathrm{l}$ \\
\hline$\left[-\mathrm{SO}_{3} \mathrm{H}\right]$ & $0.00-0.15 \mathrm{~mol} / \mathrm{l}$ \\
\hline Catalyst loading & $0.00-22.00 \mathrm{~g} / \mathrm{l}$ \\
\hline
\end{tabular}

Table 2 introduces the characteristic of Amerberlite IR-120.

Table 2. Amberlite IR-120 properties

Polymer type

Cross linking [\%]

Moisture content [wt-\%]

Capacity by dry weight [meq/g]

Native particle size range [mm]
Gel

8

45

4.4

$0.3-1.2$

\subsection{Analytical methods}

Samples were withdrawn from the reaction mixture by a plastic syringe (to avoid contamination of the solution by trace of metals) and they were analyzed by the Greenspan and Mackellar method [14]. The concentration of hydrogen peroxide was determined by titration using a standard solution of ammonium cerium 
sulfate $(0.1 \mathrm{~N})$. The concentrations of formic and peroxyformic acids were determined by titration with an automatic titrator using a standard solution of sodium hydroxide $(0.2 \mathrm{~N})$. 


\section{RESULTS AND DISCUSSION}

\subsection{Equilibrium analysis}

Based on the previous work of our group [15], the true thermodynamic constant $\mathrm{K}^{\top}$ follows the law of van't Hoff,

$\ln \frac{\mathrm{K}^{\mathrm{T}}}{\mathrm{K}_{\mathrm{ref}}^{\mathrm{T}}}=\frac{-\Delta \mathrm{H}_{\mathrm{r}}^{\mathrm{o}}}{\mathrm{R}}\left(\frac{1}{\mathrm{~T}}-\frac{1}{\mathrm{~T}_{\mathrm{ref}}}\right)$

where $\Delta \mathrm{H}_{\mathrm{r}}^{\circ}$ stands for the standard reaction enthalpy. Assuming that $\Delta \mathrm{H}_{\mathrm{r}}^{\circ}$ is independent of $\mathrm{T}$ within the temperature range of $30-70^{\circ} \mathrm{C}$.

Equilibrium experiments were carried out to determine the value of the equilibrium constant $\mathrm{K}^{\mathrm{c}}$, which is equal to $\mathrm{K}^{\mathrm{C}}=\frac{[\mathrm{PFA}]_{\mathrm{eq}} \cdot\left[\mathrm{H}_{2} \mathrm{O}\right]_{\mathrm{eq}}}{[\mathrm{FA}]_{\text {eq }} \cdot\left[\mathrm{H}_{2} \mathrm{O}_{2}\right]_{\mathrm{eq}}}$. Due to the high instability of peroxyformic acid, $\mathrm{K}^{\mathrm{c}}$ was determined at the lowest temperature, i.e., $30^{\circ} \mathrm{C}$, and this value was found to be equal to 0.96 . The equilibrium constant calculated based on concentration $\mathrm{K}^{\mathrm{c}}$ can be assumed to be equal to the thermodynamic equilibrium constant $\mathrm{K}^{\top}$ [15]. The value of $\Delta \mathrm{H}_{\mathrm{r}}^{\circ}$ was estimated by the model. 


\subsection{Mass transfer effects}

No external mass transfer resistance was noticed in the range of 100-300 rpm. Internal mass transfers were studied by using Weisz-Prater criterion :

$$
C_{W-P}=\frac{r_{o b s} \cdot L^{2}}{D_{\text {eff }} \cdot C_{b}}\left(\frac{\mathrm{n}+1}{2}\right)
$$

where robs is the observed reaction rate corresponding to the formation of peroxyformic acid, $\mathrm{C}_{\mathrm{b}}$ is the concentration of formic acid at the catalyst surface, equal to bulk surface because there is no external mass transfer, Deff is the effective diffusion coefficient of formic acid and $L$ is the ratio $V_{p} / A p$. The effective diffusion coefficient is defined as $D_{e}=\left(\varepsilon_{P} / \tau\right) D$ where $\varepsilon_{P}$ and $\tau$ are the porosity and tortuosity of the material. In case of Amberlite IR-120, the porosity is equal to 0.5 and tortuosity is 2.2 [16]. The molecular diffusion $D$ of formic acid was estimated by using Wilke-Chang equation $\left(3.10^{-9} \mathrm{~m}^{2} / \mathrm{s}\right.$ at $\left.50^{\circ} \mathrm{C}\right)$.

To evaluate the importance of the internal mass transfer a batch experiment was carried out at $50^{\circ} \mathrm{C}$ with 10 grams of dry catalyst. The initial concentration of both reactants were $6.6 \mathrm{~mol} / \mathrm{l}$ and the bigger particle diameter of $1.2 \mathrm{~mm}$ was used. At the beginning of the reaction a second order reaction rate was assumed to be. The observed initial rate was measured to be $0.0049 \mathrm{~mol} / / / \mathrm{min}$. Thus, WeiszPrater criterion is equal to 0.065 , which is very low. One can neglect the internal mass transfer effect. 


\subsection{Mechanism and kinetic equations}

Based on the observations reported in our previous articles [17-18], two processes take place simultaneously, perhydrolysis and decomposition reactions.

The synthesis of peroxyformic acid from formic acid and hydrogen peroxide is a reversible reaction,

$$
\begin{gathered}
\text { Perhydrolysis } \\
\mathrm{HCOOH}+\mathrm{H}_{2} \mathrm{O}_{2} \rightleftarrows \mathrm{HCO}_{3} \mathrm{H}+\mathrm{H}_{2} \mathrm{O}
\end{gathered}
$$

Hydrolysis

The forward way corresponds to the synthesis reaction, whereas the reverse way is the reaction of water with peroxyformic acid. One should not confuse hydrolysis and decomposition reaction, which corresponds to the decomposition of peroxyformic acid to several products.

A characteristic feature for the synthesis reaction is that it proceeds simultaneously along a heterogeneous path (catalyzed by hydroxonium ions from cation exchange resin) and a homogeneous path (catalyzed by hydroxonium ions from the formic acid dissociation). A simplified mechanism showing the different steps of peroxyformic acid synthesis is shown on Fig. 2 . 


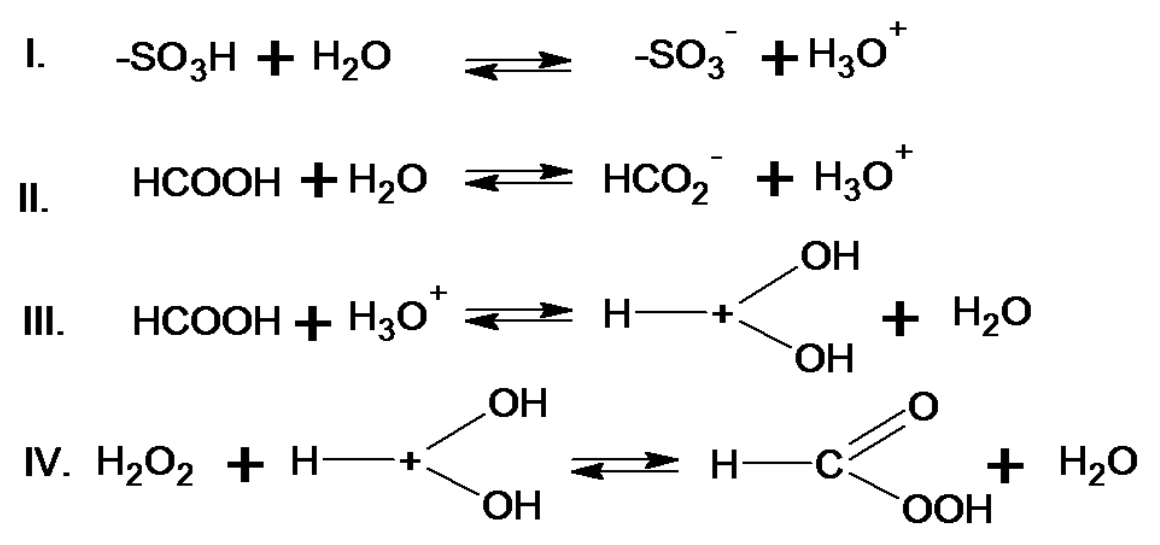

Figure 2. Simplified mechanism of peroxyformic synthesis.

For the homogeneous path (reaction II.) and heterogeneous path (reaction I.), the quasi-equilibrium analysis hypothesis. By deriving the mass balance and using the electroneutrality equation on the formic acid species and sulfonic group beared by Amberlite IR-120 [15], the rate of the homogeneous reaction can be expressed as:

$$
r_{\text {hom }}=\frac{k_{\text {hom }} \sqrt{\mathrm{K}_{\mathrm{FAD}}^{\mathrm{c}}[\mathrm{HCOOH}]\left[\mathrm{H}_{2} \mathrm{O}\right]}}{\left[\mathrm{H}_{2} \mathrm{O}\right]}\left([\mathrm{HCOOH}]\left[\mathrm{H}_{2} \mathrm{O}_{2}\right]-\frac{1}{\mathrm{~K}^{\mathrm{c}}}\left[\mathrm{HCO}_{3} \mathrm{H}\right]\left[\mathrm{H}_{2} \mathrm{O}\right]\right)
$$

where, khom is the rate constant taking into account the dissociation of formic acid, $\mathrm{K}^{\mathrm{c}}$ is the equilibrium parameter and $\mathrm{K}_{\mathrm{FAD}}^{\mathrm{c}}$ (formic acid dissociation, $\mathrm{FAD}$ ) can be expressed as:

$$
\mathrm{K}_{\mathrm{FAD}}^{\mathrm{c}}=\frac{\mathrm{K}_{\mathrm{FAD}}^{\top}}{55.5}
$$

where, $\mathrm{K}_{\mathrm{FAD}}^{\top}$ is the true thermodynamic constant in case of infinite dilution and $55.5 \mathrm{~mol} / \mathrm{l}$ is the water concentration at infinite dilution. The contribution of the product, i.e., peroxyformic acid, to the acid catalysis step IV was neglected since it is a weaker acid than formic acid. 
The rate of the heterogeneous path can be expressed as:

$r_{\text {het }}=\frac{k_{\text {het }} \sqrt{\mathrm{K}_{\mathrm{l}}^{\mathrm{c}}\left[-\mathrm{SO}_{3} \mathrm{H}\right]\left[\mathrm{H}_{2} \mathrm{O}\right]}}{\left[\mathrm{H}_{2} \mathrm{O}\right]}\left([\mathrm{HCOOH}]\left[\mathrm{H}_{2} \mathrm{O}_{2}\right]-\frac{1}{\mathrm{~K}^{\mathrm{c}}}\left[\mathrm{HCO}_{3} \mathrm{H}\right]\left[\mathrm{H}_{2} \mathrm{O}\right]\right)$

For the sake of simplicity, the first term of Eq.(3) was lumped as:

$$
\mathrm{k}_{\mathrm{hom}}^{\prime}=\mathrm{k}_{\mathrm{hom}} \sqrt{\mathrm{K}_{\mathrm{FAD}}^{\mathrm{c}}}
$$

and the term of Eq.(5) was lumped as:

$\mathrm{k}_{\text {het }}^{\prime}=\mathrm{k}_{\text {het }} \sqrt{\mathrm{K}_{\mathrm{l}}^{\mathrm{C}}}$

The value of $\mathrm{K}_{1}^{\mathrm{C}}$ is $3.19 \cdot 10^{-6}$ at $25^{\circ} \mathrm{C}$ and $2.79 \cdot 10^{-6}$ at $60^{\circ} \mathrm{C}$, which is virutaly constant. [19]

By adding Eqs. (3) and (5), we obtain:

$$
\begin{aligned}
r_{\text {perh }} & =r_{\text {hom }}+r_{\text {het }} \\
& =\left(k_{\text {hom }}^{\prime} * \sqrt{\frac{[\mathrm{HCOOH}]}{\left[\mathrm{H}_{2} \mathrm{O}\right]}}+k_{\text {het }}^{\prime} * \sqrt{\left.\frac{\left[-\mathrm{SO}_{3} \mathrm{H}\right]}{\left[\mathrm{H}_{2} \mathrm{O}\right]}\right)}\right)\left([\mathrm{HCOOH}]\left[\mathrm{H}_{2} \mathrm{O}_{2}\right]-\frac{1}{\mathrm{~K}^{\mathrm{C}}}\left[\mathrm{HCO}_{3} \mathrm{H}\right]\left[\mathrm{H}_{2} \mathrm{O}\right]\right)
\end{aligned}
$$

Based on a literature review [12], several ways of decomposition for peroxyformic acid might occur. Based on our observations, only the direct decomposition mechanism has to take into account under the actual experimental conditions:

$$
\begin{aligned}
& \mathrm{HCO}_{3} \mathrm{H} \longrightarrow \mathrm{H}_{2} \mathrm{O}+\mathrm{CO}_{2} \\
& \mathrm{r}_{\text {decomp }}=\mathrm{k}_{\text {decomp }} \cdot\left[\mathrm{HCO}_{3} \mathrm{H}\right]
\end{aligned}
$$

The constants khom, khet and kdecomp were estimated in our model. 


\subsection{Mass balance for a semi-batch reactor}

In case of a semi-batch reactor, the mass balance can be written as

$$
\dot{\mathrm{n}}_{\mathrm{j}, \mathrm{in}}+\sum v_{\mathrm{ij}} \mathrm{V}_{\mathrm{R}} \cdot \mathrm{r}_{\mathrm{i}}=\frac{\mathrm{dn}}{\mathrm{dt}}
$$

where $V_{R}$ is the reaction volume, $\dot{n}$ is the molar flow rate, $r_{i}$ is the generation rate and $\mathrm{dn}_{j} / \mathrm{dt}$ is the accumulation term.

In case of formic acid, the mass balance becomes

$$
\mathrm{Q}_{\mathrm{HCOOH}} \cdot[\mathrm{HCOOH}]_{\mathrm{f}}-r_{\text {perh }} \cdot V_{\mathrm{R}}=\frac{d\left([\mathrm{HCOOH}] \cdot V_{\mathrm{R}}\right)}{d t}
$$

where $[\mathrm{HCOOH}] \mathrm{f}$ is the concentration of formic acid in the feed, $[\mathrm{HCOOH}]$ is the concentration at time $t$ in the reactor, $\mathrm{QHCOOH}_{\mathrm{H}} \mathrm{Q}_{\mathrm{f}}$ is the volumetric flow rate and $V_{R}$ is the reaction volume being equal to $V_{R}=Q_{f} \cdot \int_{t=0}^{t=t_{\text {add }}} d t+V_{0}$

Eq. 11 becomes

$\mathrm{Q}_{\mathrm{f}} \cdot[\mathrm{HCOOH}]_{\mathrm{f}}-\mathrm{r}_{\text {perh }} \cdot \mathrm{V}_{\mathrm{R}}=\mathrm{V}_{\mathrm{R}} \frac{\mathrm{d}[\mathrm{HCOOH}]}{\mathrm{dt}}+[\mathrm{HCOOH}] \frac{\mathrm{dV}_{\mathrm{R}}}{\mathrm{dt}}$

$\frac{d V_{R}}{d t}$ is the volumetric flow rate $Q_{f}$ giving

$$
\frac{\mathrm{d}[\mathrm{HCOOH}]}{\mathrm{dt}}=\frac{\mathrm{Q}_{\mathrm{f}}}{\mathrm{V}_{\mathrm{R}}} \cdot\left([\mathrm{HCOOH}]_{\mathrm{f}}-[\mathrm{HCOOH}]\right)-\mathrm{r}_{\text {perh }}
$$

The mass balances for hydrogen peroxide, peroxyformic acid and water are:

$$
\begin{aligned}
& \frac{\mathrm{d}\left[\mathrm{H}_{2} \mathrm{O}_{2}\right]}{\mathrm{dt}}=-\frac{\mathrm{Q}_{\mathrm{f}}}{\mathrm{V}_{\mathrm{R}}} \cdot\left[\mathrm{H}_{2} \mathrm{O}_{2}\right]-\mathrm{r}_{\text {perh }} \\
& \frac{\mathrm{d}\left[\mathrm{HCO}_{3} \mathrm{H}\right]}{\mathrm{dt}}=-\frac{\mathrm{Q}_{\mathrm{f}}}{\mathrm{V}_{\mathrm{R}}} \cdot\left[\mathrm{HCO}_{3} \mathrm{H}\right]+\left(\mathrm{r}_{\text {perh }}-\mathrm{r}_{\text {decomp }}\right)
\end{aligned}
$$


$\frac{\mathrm{d}\left[\mathrm{H}_{2} \mathrm{O}\right]}{\mathrm{dt}}=-\frac{\mathrm{Q}_{\mathrm{f}}}{\mathrm{V}_{\mathrm{R}}} \cdot\left[\mathrm{H}_{2} \mathrm{O}\right]+\left(\mathrm{r}_{\text {perh }}+\mathrm{r}_{\text {decomp }}\right)$

Eqs. (13), (14), (15) and (16) were included in the model. 


\subsection{Energy balance}

Fig. 3 displays the heat effects being present in a calorimetric reactor, where the heat effect due to the shaft work is negligible.

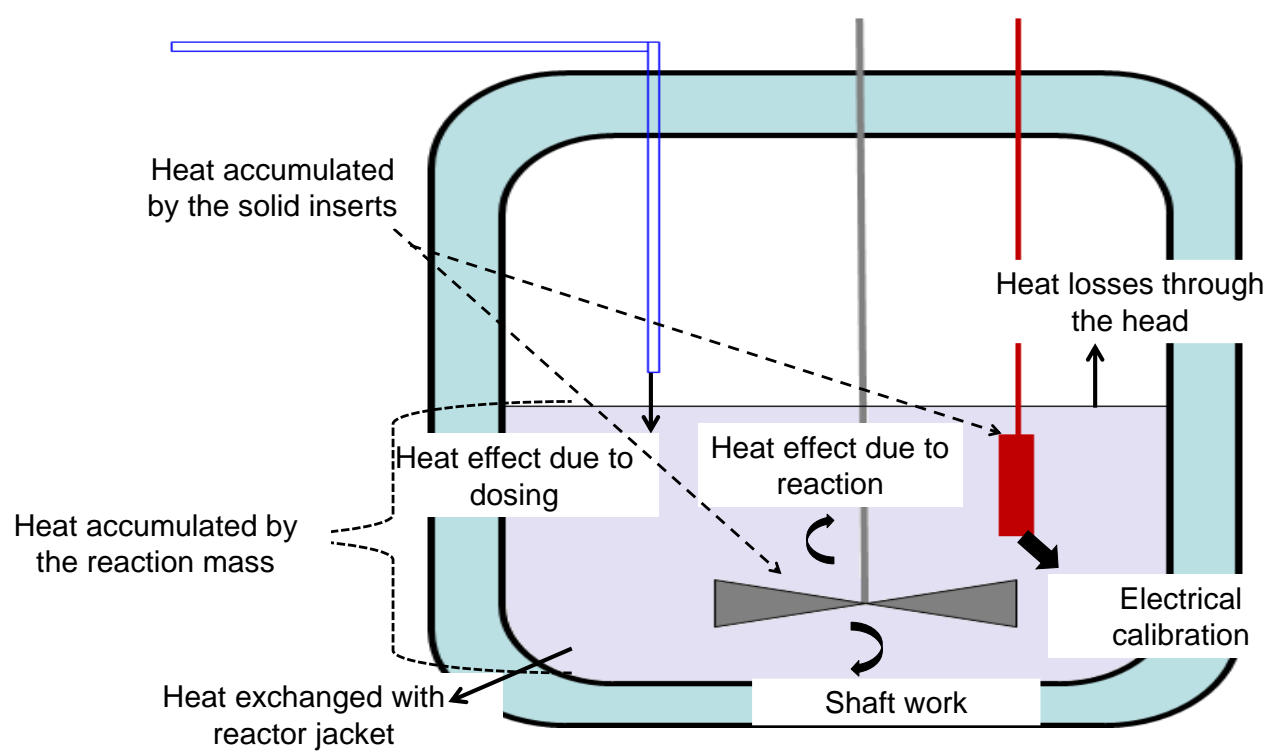

Figure 3. Schematic view of energy

The energy balance for a semi-batch reactor is equal to:

$$
\mathrm{V}_{\mathrm{R}} \cdot \rho_{\mathrm{R}} \cdot \hat{\mathrm{C}}_{\mathrm{PR}} \cdot \frac{\mathrm{dT}_{\mathrm{R}}}{\mathrm{dt}}=-\sum_{\mathrm{i}} \mathrm{r}_{\mathrm{i}} \cdot \Delta H_{\mathrm{Ri}} \cdot \mathrm{V}_{\mathrm{R}}+\mathrm{C}_{\mathrm{jf}} \cdot \mathrm{Q}_{\mathrm{f}} \cdot \overline{\mathrm{C}}_{\mathrm{pj}} \cdot\left(\mathrm{T}_{\mathrm{f}}-\mathrm{T}_{\mathrm{R}}\right)+\dot{\mathrm{Q}}
$$

where $\hat{C}_{P}$ is constant-pressure specific heat capacity per mass, $V_{R}$ is the volume of the reaction system, $\rho_{\mathrm{R}}$ is the mass density of the reaction system, $\overline{\mathrm{H}}_{\mathrm{j}}$ is the molar reaction enthalpy, $\dot{\mathrm{Q}}$ is the heat flux exchanged $\left(\dot{\mathrm{Q}}_{\mathrm{ex}}\right)$ with the reactor jacket and the one lost through the top of the reactor $\left(\dot{Q}_{\text {loss }}\right)$,

$$
\dot{\mathrm{Q}}=\dot{\mathrm{Q}}_{\mathrm{ex}}+\dot{\mathrm{Q}}_{\mathrm{loss}}
$$


According to Milewska and Molga [20], these two heat transfer terms can be expressed as

$$
\dot{\mathrm{Q}}=\mathrm{U} \cdot \mathrm{A} \cdot\left(\mathrm{T}_{\mathrm{J}}-\mathrm{T}_{\mathrm{R}}\right)+\mathrm{U}_{\mathrm{A}} \mathrm{A}_{\text {loss }} \cdot\left(\mathrm{T}_{\mathrm{O}}-\mathrm{T}_{\mathrm{R}}\right)
$$

where, $U$ is the overall heat transfer coefficient, $T_{J}$ is the temperature of the jacket, To is the temperature of the top of the reactor and $A$ and Aloss denotes the heat transfer area. According to Ulbrich et al. [21], the heat loss through the top of the reactor is mainly due to the evaporation of the reaction mixture. Some of the vapour produced may condense at the cold cover and cold droplets flow back to the reactor. This can be considered to be the major contribution to heat losses. Based on the research of Ubrich et al. [21], the heat losses can be estimated as :

$$
\dot{\mathrm{Q}}_{\mathrm{loss}}=\beta \cdot \sum_{\mathrm{j}} \mathrm{x}_{\mathrm{i}} \mathrm{P}_{\mathrm{j}}
$$

$\beta\left[\mathrm{J}^{\mathrm{s}} \mathrm{s}^{-1} \cdot \mathrm{atm}^{-1}\right]$ is a paremeter taking into account the evaporation and condensation phenomena, $x_{j}$ is the mole fraction in the liquid phase of compound $\mathrm{j}$ and $\mathrm{PJ}$ is the vapour pressure of the compound $\mathrm{J}$. Pj can be estimated by a Clausius Clapeyron relation :

$$
\mathrm{P}\left(\mathrm{T}_{1}\right)=\mathrm{P}\left(\mathrm{T}_{2}\right) \exp \left(\frac{\Delta \mathrm{H}_{v}}{R} \cdot\left(\frac{1}{\mathrm{~T}_{1}}-\frac{1}{\mathrm{~T}_{2}}\right)\right)
$$

where $\Delta H_{v}$ is the heat of vaporisation, $R$ the general gas constant, $P\left(T_{1}\right)$ and $\mathrm{P}\left(\mathrm{T}_{2}\right)$, the vapor pressure at temperature $\mathrm{T} 1$ and $\mathrm{T} 2$, respectively.

From Fig. 4, one can notice that formic acid and water are the most volatile compound. For that reason, Eq.(20) was applied for these compounds. 


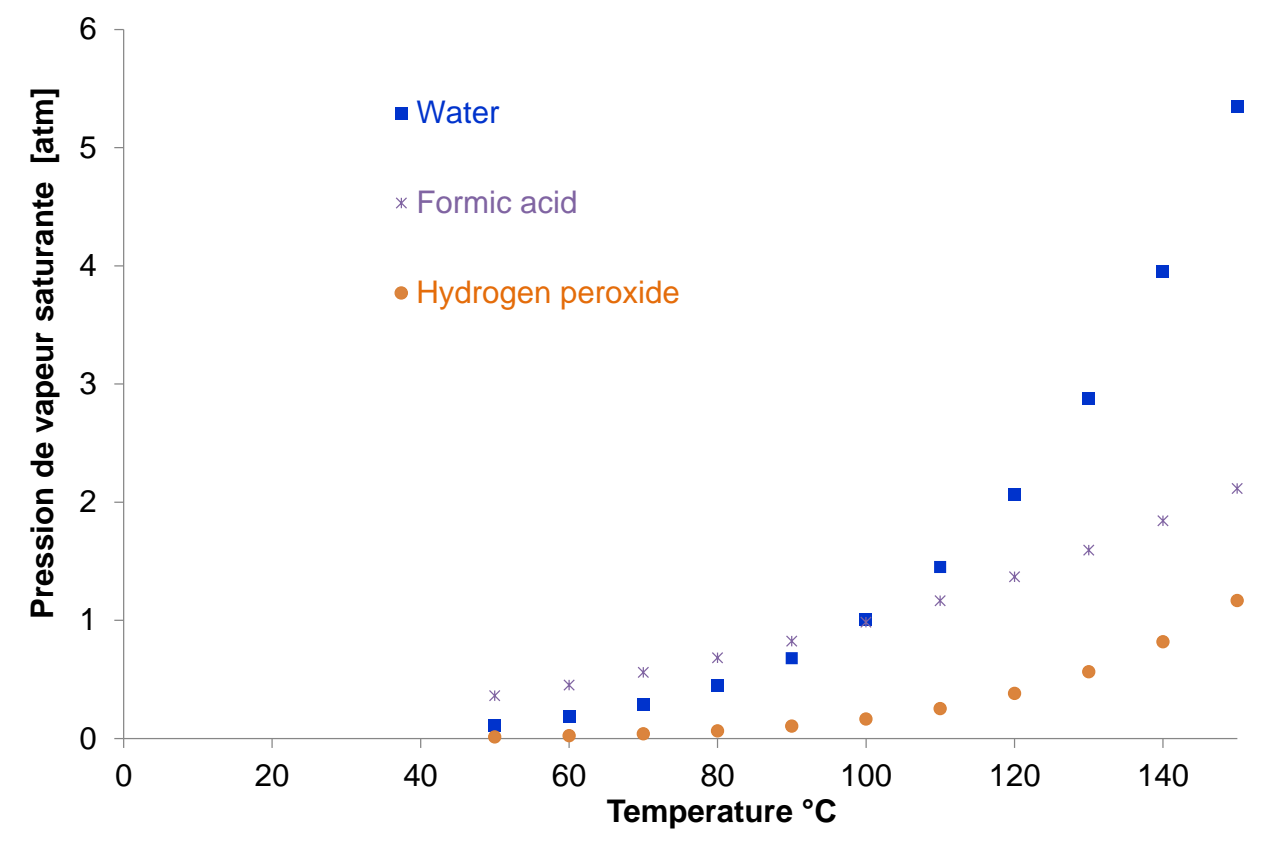

Figure 4. Vapor pressure of water, formic acid and hydrogen peroxide at different temperatures.

Eq. (17) becomes

$$
\begin{aligned}
& \mathrm{V}_{\mathrm{R}} \cdot \rho_{\mathrm{R}} \cdot \hat{\mathrm{C}}_{\mathrm{PR}} \cdot \frac{\mathrm{dT}_{\mathrm{R}}}{\mathrm{dt}}=-\sum_{\mathrm{i}} \mathrm{r}_{\mathrm{i}} \cdot \Delta H_{\mathrm{Ri}} \cdot \mathrm{V}_{\mathrm{R}}+\mathrm{C}_{\mathrm{jf}} \cdot \mathrm{Q}_{\mathrm{f}} \cdot \overline{\mathrm{C}}_{\mathrm{pj}} \cdot\left(\mathrm{T}_{\mathrm{f}}-\mathrm{T}_{\mathrm{R}}\right)+\mathrm{U} \cdot \mathrm{A} \cdot\left(\mathrm{T}_{\mathrm{j}}-\mathrm{T}_{\mathrm{R}}\right)+\beta \cdot\left(\mathrm{x}_{\mathrm{FA}} \cdot \mathrm{P}_{\mathrm{FA}}+\mathrm{x}_{\mathrm{W}} \cdot \mathrm{P}_{\mathrm{W}}\right) \\
& \Leftrightarrow \mathrm{m}_{\mathrm{R}} \cdot \hat{\mathrm{C}}_{\mathrm{PR}} \cdot \frac{\mathrm{dT}_{\mathrm{R}}}{\mathrm{dt}}=-\sum_{\mathrm{i}} \mathrm{r}_{\mathrm{i}} \cdot \Delta H_{\mathrm{Ri}} \cdot \mathrm{V}_{\mathrm{R}}+\mathrm{m}_{\mathrm{jf}} \cdot \hat{\mathrm{C}}_{\mathrm{Pj}} \cdot\left(\mathrm{T}_{\mathrm{f}}-\mathrm{T}_{\mathrm{R}}\right)+\mathrm{U} \cdot \mathrm{A} \cdot\left(\mathrm{T}_{\mathrm{j}}-\mathrm{T}_{\mathrm{R}}\right)+\beta \cdot\left(\mathrm{x}_{\mathrm{FA}} \cdot \mathrm{P}_{\mathrm{FA}}+\mathrm{x}_{\mathrm{W}} \cdot \mathrm{P}_{\mathrm{W}}\right)
\end{aligned}
$$

In our study, the term $\bar{C}_{p j} \cdot\left(T_{f}-T_{R}\right)$ was considered to be negligible, since the initial reactor temperature was equal to that of the inlet fluid and the formic acid addition was completed before a significant reactor temperature increase. Two reactions take place during the synthesis of peroxyformic acid as mentioned earlier, thus Eq. (22) is reduced to 
$\mathrm{m}_{\mathrm{R}} \cdot \hat{\mathrm{C}}_{\mathrm{PR}} \cdot \frac{\mathrm{dT}_{\mathrm{R}}}{\mathrm{dt}}=-\left(\mathrm{r}_{\mathrm{perh}} \cdot \Delta \mathrm{H}_{\mathrm{Rperh}}+\mathrm{r}_{\text {decomp }} \cdot \Delta \mathrm{H}_{\mathrm{Rdecomp}}\right) \cdot \mathrm{V}_{\mathrm{R}}+\mathrm{U} \cdot \mathrm{A} \cdot\left(\mathrm{T}_{\mathrm{j}}-\mathrm{T}_{\mathrm{R}}\right)+\beta \cdot\left(\mathrm{x}_{\mathrm{FA}} \cdot \mathrm{P}_{\mathrm{FA}}+\mathrm{x}_{\mathrm{W}} \cdot \mathrm{P}_{\mathrm{W}}\right)$ (23)

The reaction enthalpies and parameter $\beta$ were estimated by our model.

\subsection{Experimental determination of U.A and $\hat{C}_{p j}$}

By using the electrical calibration, i.e., the Joule heating, it was possible to determine experimentally the parameters U.A and $\hat{\mathrm{C}}_{\mathrm{pj}}$. Eq. (17) becomes:

$\mathrm{V}_{\mathrm{R}} \cdot \rho_{\mathrm{R}} \cdot \hat{\mathrm{C}}_{\mathrm{PR}} \cdot \frac{\mathrm{dT} \mathrm{T}_{\mathrm{R}}}{\mathrm{dt}}=-\sum_{\mathrm{i}} \mathrm{r}_{\mathrm{i}} \cdot \Delta H_{\mathrm{Ri}} \cdot \mathrm{V}_{\mathrm{R}}+\mathrm{C}_{\mathrm{jf}} \cdot \mathrm{Q}_{\mathrm{f}} \cdot \overline{\mathrm{C}}_{\mathrm{pj}} \cdot\left(\mathrm{T}_{\mathrm{f}}-\mathrm{T}_{\mathrm{R}}\right)+\dot{\mathrm{Q}}_{\mathrm{loss}}+\dot{\mathrm{Q}}_{\mathrm{ex}}+\dot{\mathrm{Q}}_{\mathrm{c}}$

where $\dot{\mathrm{Q}}_{\mathrm{c}}$ is the electrical calibration performed before and at the end of the experiments. Calibration was performed in absence of chemical reaction, in absence of reactant feeding and in a temperature range where evaporation can be neglected. Thus, one gets

$\mathrm{m}_{\mathrm{R}} \cdot \hat{\mathrm{C}}_{\mathrm{PR}} \cdot \frac{\mathrm{dT} \mathrm{T}_{\mathrm{R}}}{\mathrm{dt}}=\mathrm{U} \cdot \mathrm{A} \cdot\left(\mathrm{T}_{\mathrm{j}}-\mathrm{T}_{\mathrm{R}}\right)+\dot{\mathrm{Q}}_{\mathrm{C}}$ 


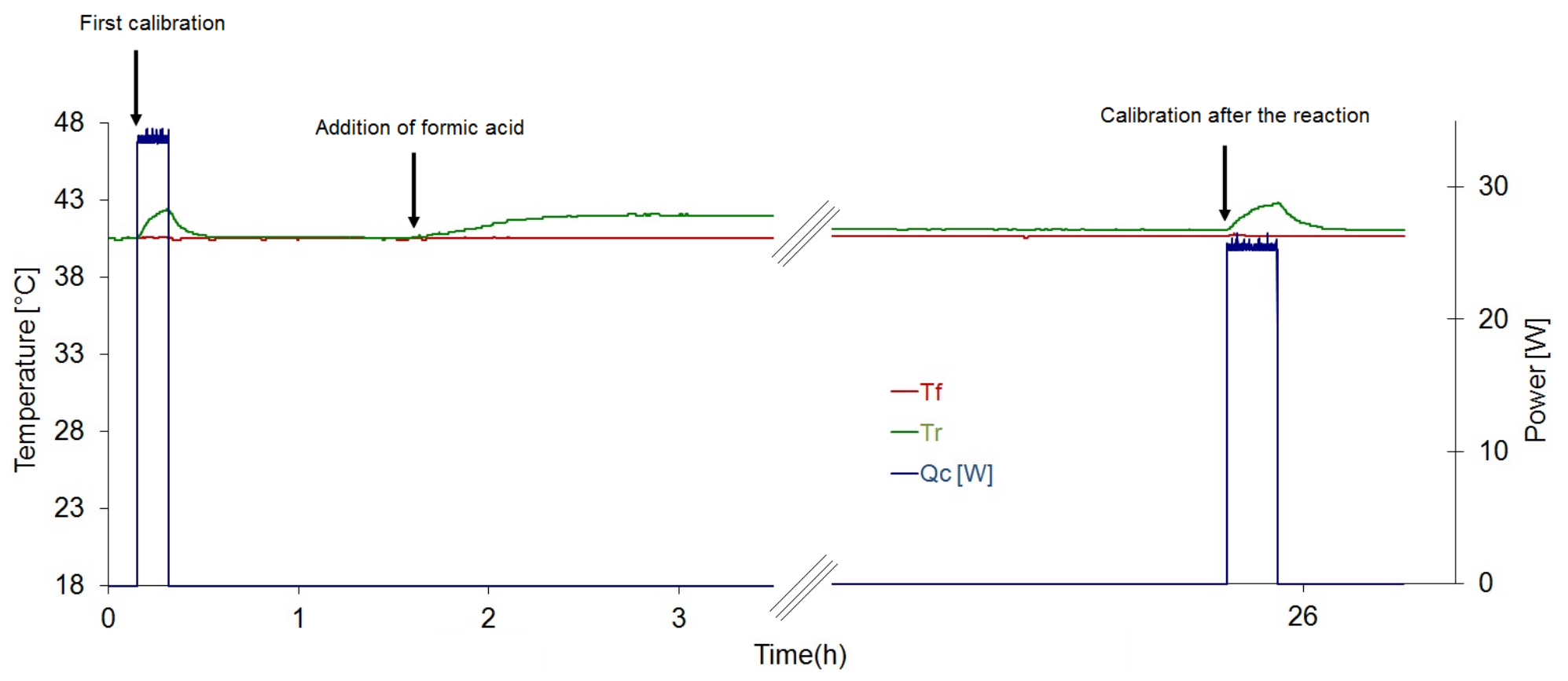

Figure 5. Temperature evolution during an experiment.

Figure 5 shows a classical example of the temperature versus time pattern obtained during an experiment..In the first stage, hydrogen peroxide and water were added into the reactor. As the desired temperature was reached, the electrical calibration was switched on.

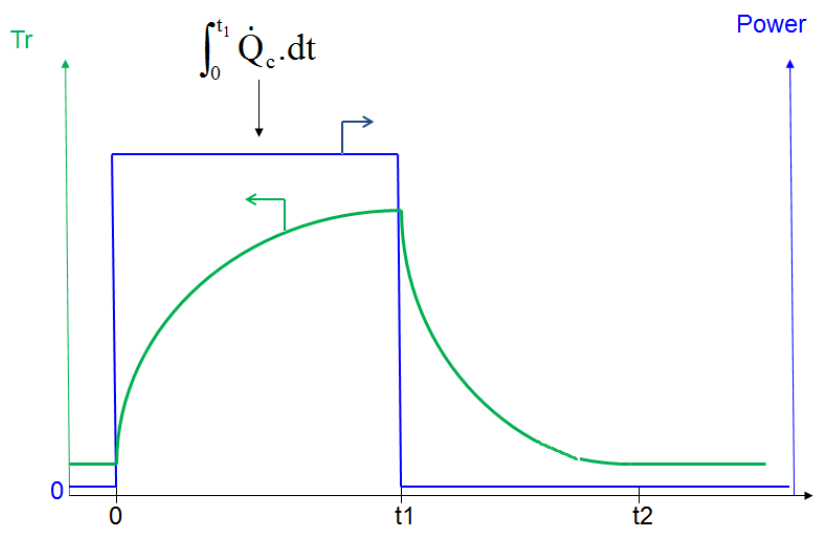

Figure 6. Calibration step 
Figure 6 is an illustrated example of the calibration step, one can derive the energy balance from the beginning of the calibration (0) to the desired temperature (at $\left.t_{2}\right)$,

$$
\mathrm{m}_{\mathrm{R}} \cdot \hat{\mathrm{C}}_{\mathrm{PR}_{\mathrm{R}}} \cdot \frac{\mathrm{dT}_{\mathrm{R}}}{\mathrm{dt}}=\mathrm{U} \cdot \mathrm{A} \cdot\left(\mathrm{T}_{\mathrm{j}}-\mathrm{T}_{\mathrm{R}}\right)+\dot{\mathrm{Q}}_{\mathrm{C}}=0 \Leftrightarrow \mathrm{U} \cdot \mathrm{A} \cdot=\frac{-\int_{0}^{\mathrm{t}_{2}} \dot{\mathrm{Q}}_{\mathrm{C}} \cdot \mathrm{dt}}{\int_{0}^{\mathrm{t}_{2}}\left(\mathrm{~T}_{\mathrm{j}}-\mathrm{T}_{\mathrm{R}}\right) \cdot \mathrm{dt}}
$$

The specific heat capacity of the reaction mixture was calculated by considering the cooling curve from $t_{1}$ to $t_{2}$. The following energy balance is obtained

$$
\mathrm{m}_{\mathrm{R}} \cdot \hat{\mathrm{C}}_{\mathrm{PR}} \cdot \frac{\mathrm{dT}}{\mathrm{dt}}=\mathrm{U} \cdot \mathrm{A} \cdot\left(\mathrm{T}_{\mathrm{j}}-\mathrm{T}_{\mathrm{R}}\right) \Leftrightarrow \hat{\mathrm{C}}_{\mathrm{PR}}=-\frac{\mathrm{U} \cdot \mathrm{A}}{\mathrm{m}_{\mathrm{R}}} \cdot \ln \left(\frac{\left(\mathrm{T}_{\mathrm{R}, \mathrm{t}_{1}}-\mathrm{T}_{\mathrm{j}, \mathrm{t}_{1}}\right)}{\left(\mathrm{T}_{\mathrm{R}, \mathrm{t}}-\mathrm{T}_{\mathrm{j}, \mathrm{t}}\right)}\right) \mathrm{t}
$$

By using Eq. 27, it was possible to determine $\hat{\mathrm{C}}_{\mathrm{PR}_{\mathrm{R}}}$ before the addition of formic acid and at the end of the thermal evolution. Table 2 shows the values of $\hat{\mathrm{C}}_{\mathrm{PR}}$ and U.A for different reactions.

Table 3. Thermal parameters of the reactor

\begin{tabular}{|c|c|c|c|c|}
\cline { 2 - 5 } \multicolumn{1}{c|}{} & Tinitial $[\mathrm{K}]$ & 303.15 & 313.15 & 323.15 \\
\hline \multirow{2}{*}{ Before addition } & U.A. $[\mathrm{W} / \mathrm{K}]$ & 4.57 & 4.02 & 4.38 \\
\cline { 2 - 5 } & $\hat{\mathrm{C}}_{\mathrm{PR}}[\mathrm{J} / \mathrm{kg} / \mathrm{K}]$ & 2424 & 2447 & 2646 \\
\hline \multirow{2}{*}{ End of reaction } & $\mathrm{U} . \mathrm{A} .[\mathrm{W} / \mathrm{K}]$ & 3.17 & 4.51 & 4.14 \\
\cline { 2 - 5 } & $\hat{\mathrm{C}}_{\mathrm{PR}}[\mathrm{J} / \mathrm{kg} / \mathrm{K}]$ & 1981 & 1950 & 2030 \\
\hline
\end{tabular}

One should notice that the value of U.A does not change significantly during the reaction. However, the value of $\hat{\mathrm{C}}_{\mathrm{PR}}$ of the reaction solution changes with the 
reaction composition. The specific heat capacity was supposed to evolve linearly with the conversion of one reactant as

$$
\hat{\mathrm{C}}_{\mathrm{PR}}=\alpha \cdot X_{\mathrm{H}_{2} \mathrm{O}_{2}}+\left(\hat{\mathrm{C}}_{\mathrm{PR}}\right)_{0}
$$

where $\alpha$ is a coefficient determined from the experiment data, $X_{\mathrm{H}_{2} \mathrm{O}_{2}}$ is the conversion of hydrogen peroxide equal to $\frac{\left[\mathrm{H}_{2} \mathrm{O}_{2}\right]_{0}-\left[\mathrm{H}_{2} \mathrm{O}_{2}\right]}{\left[\mathrm{H}_{2} \mathrm{O}_{2}\right]_{0}}$ and $\left(\hat{\mathrm{C}}_{\mathrm{PR}}\right)_{0}$ is the initial specific heat capacity.

\subsection{Modelling and statistical results}

The ODEs 13-16 and 23 were solved numerically by a special software MODEST [22]. The objective function $\omega$ was minimized by using Simplex and Levenberg-Marquardt algorithms. The objective function was defined as follows $\omega=\Sigma\left(\mathrm{C}_{\mathrm{i}}-\hat{\mathrm{C}}_{\mathrm{i}}\right)^{2}$ where $\mathrm{C}_{i}$ is the experimental concentration and $\hat{\mathrm{C}}$ is the estimated concentration obtained from the model. The concentrations of FA, PFA and $\mathrm{H}_{2} \mathrm{O}_{2}$ were included in the objective function with equal weights. The temperature dependences of the rate constants were described by a modified Arrhenius equation:

$$
\mathrm{k}=\mathrm{k}_{\text {are }} \exp \left(\frac{-\mathrm{Ea}}{\mathrm{R}}\left(\frac{1}{\mathrm{~T}}-\frac{1}{\mathrm{~T}_{\text {ave }}}\right)\right)
$$


where $k_{a v e}=A e^{-\left(\frac{E a}{R T_{a v}}\right)}, T_{\text {ave }}$ is the average temperature of the set of experiments. The goal of this modification was to minimize the correlation between the frequency factor and the activation energy during the parameter estimation.

The coefficient of determination of the model is defined as follows

$$
\mathrm{R}^{2}=1-\frac{\sum\left(\mathrm{C}_{\mathrm{i}}-\hat{\mathrm{C}}_{\mathrm{i}}\right)^{2}}{\sum\left(\mathrm{C}_{\mathrm{i}}-\overline{\mathrm{C}}_{\mathrm{i}}\right)^{2}}
$$

where $C_{i}$ is the experimental concentration, $\hat{\mathrm{C}}_{\mathrm{i}}$ is the estimated concentration and $\overline{\mathrm{C}}_{\mathrm{i}}$ is the mean value of the observed concentration. The coefficient of determination of this model became $100 \%$, showing a very good correspondence between the experimental and calculated values. Table 4 gives the estimated and statistical data for the parameters.

Table 4. Estimated and statistical data at $\mathrm{T}_{\mathrm{ave}}=318.5 \mathrm{~K}$ 


\begin{tabular}{|c|c|c|c|}
\hline & Estimated & Standard error & Standard error \% \\
\hline $\mathrm{k}_{\text {ave, hom }}\left[1^{2} \cdot \mathrm{mol}^{-2} \cdot \mathrm{s}^{-1}\right]$ & $0.871 \cdot 10^{-4}$ & $0.000163 \cdot 10^{-4}$ & 0.0 \\
\hline \begin{tabular}{l|l}
$\mathrm{E}_{\mathrm{a} \text {, hom }}$ & $\left.\mathrm{J} \cdot \mathrm{mol}^{-1}\right\rfloor$ \\
\end{tabular} & 20000 & 1.03 & 0.0 \\
\hline $\mathrm{k}_{\text {ave, het }}\left[\mathrm{I}^{2} \cdot \mathrm{mol}^{-2} \cdot \mathrm{s}^{-1}\right]$ & $0.831 \cdot 10^{-4}$ & $0.000322 \cdot 10^{-4}$ & 0.0 \\
\hline $\mathrm{E}_{\mathrm{a}, \text { het }}\left[\mathrm{J} \cdot \mathrm{mol}^{-1}\right]$ & 1680 & 1.12 & 0.1 \\
\hline \begin{tabular}{l|l}
$\mathrm{k}_{\text {ave, decomp }}\left[\mathrm{s}^{-1}\right]$ \\
\end{tabular} & $0.127 \cdot 10^{-3}$ & $0.0000157 \cdot 10^{-3}$ & 0.0 \\
\hline $\mathrm{E}_{\mathrm{a}, \text { decomp }}\left[\mathrm{J}^{\prime} \mathrm{mol}^{-1}\right\rfloor$ & 95100 & 21.1 & 0.0 \\
\hline$\Delta \mathrm{H}_{\mathrm{R}_{\text {perh }}}\left[\mathrm{J} / \mathrm{mol}^{-1}\right]$ & -4840 & 0.88 & 0.0 \\
\hline$\Delta \mathrm{H}_{\mathrm{R \text {decomp }}}\left[\mathrm{J} / \mathrm{mol}^{-1}\right]$ & -217000 & 39.9 & 0.0 \\
\hline$\beta\left[{\left.\mathrm{J} \cdot \mathrm{s}^{-1} \cdot \mathrm{atm}^{-1}\right\rfloor}^{-1}\right.$ & 3.36 & 0.000988 & 0.0 \\
\hline
\end{tabular}

The correlation matrix is shown on Figure 7.

\begin{tabular}{|c|c|c|c|c|c|c|c|c|c|}
\hline & $\mathrm{k}_{\text {ave, hom }}$ & $\mathrm{E}_{\mathrm{a}, \mathrm{hom}}$ & $\mathrm{k}_{\text {ave, decomp }}$ & $\mathrm{E}_{\mathrm{a}, \text { decomp }}$ & $\Delta \mathrm{H}_{\mathrm{R} \text { decomp }}$ & $\Delta \mathrm{H}_{\mathrm{K} \text { perti }}$ & $\mathrm{k}_{\text {ave, het }}$ & $\mathrm{E}_{\mathrm{a}, \text { het }}$ & $\beta$ \\
\hline $\mathrm{k}_{\mathrm{ave}, \mathrm{hom}}$ & 1.00 & & & & & & & & \\
\hline $\mathrm{E}_{\mathrm{a} \text {, hom }}$ & -0.24 & 1.00 & & & & & & & \\
\hline $\mathrm{k}_{\text {ave, decomp }}$ & 0.31 & -0.27 & 1.00 & & & & & & \\
\hline $\mathrm{E}_{\mathrm{a}, \mathrm{decomp}}$ & -0.29 & 0.49 & -0.09 & 1.00 & & & & & \\
\hline$\Delta \mathrm{H}_{\mathrm{R} \text { decomp }}$ & 0.42 & 0.13 & -0.58 & -0.30 & 1.00 & & & & \\
\hline$\Delta H_{\mathrm{R}_{\text {pert }}}$ & 0.40 & -0.03 & -0.16 & 0.01 & 0.39 & 1.00 & & & \\
\hline $\mathrm{k}_{\text {ave, het }}$ & 0.08 & -0.01 & -0.06 & -0.05 & 0.13 & 0.16 & 1.00 & & \\
\hline $\mathrm{E}_{\mathrm{a}, \text { het }}$ & -0.23 & 0.04 & -0.34 & 0.09 & 0.05 & 0.00 & -0.04 & 1.00 & \\
\hline$\beta$ & -0.43 & -0.02 & -0.63 & 0.22 & 0.01 & 0.02 & -0.07 & 0.43 & 1.00 \\
\hline
\end{tabular}

Figure 7. Correlation matrix of parameters.

Figure 7 reveals that the correlations between the estimated parameters are small. Figure 8 shows that the model fits the experimental data very well. 

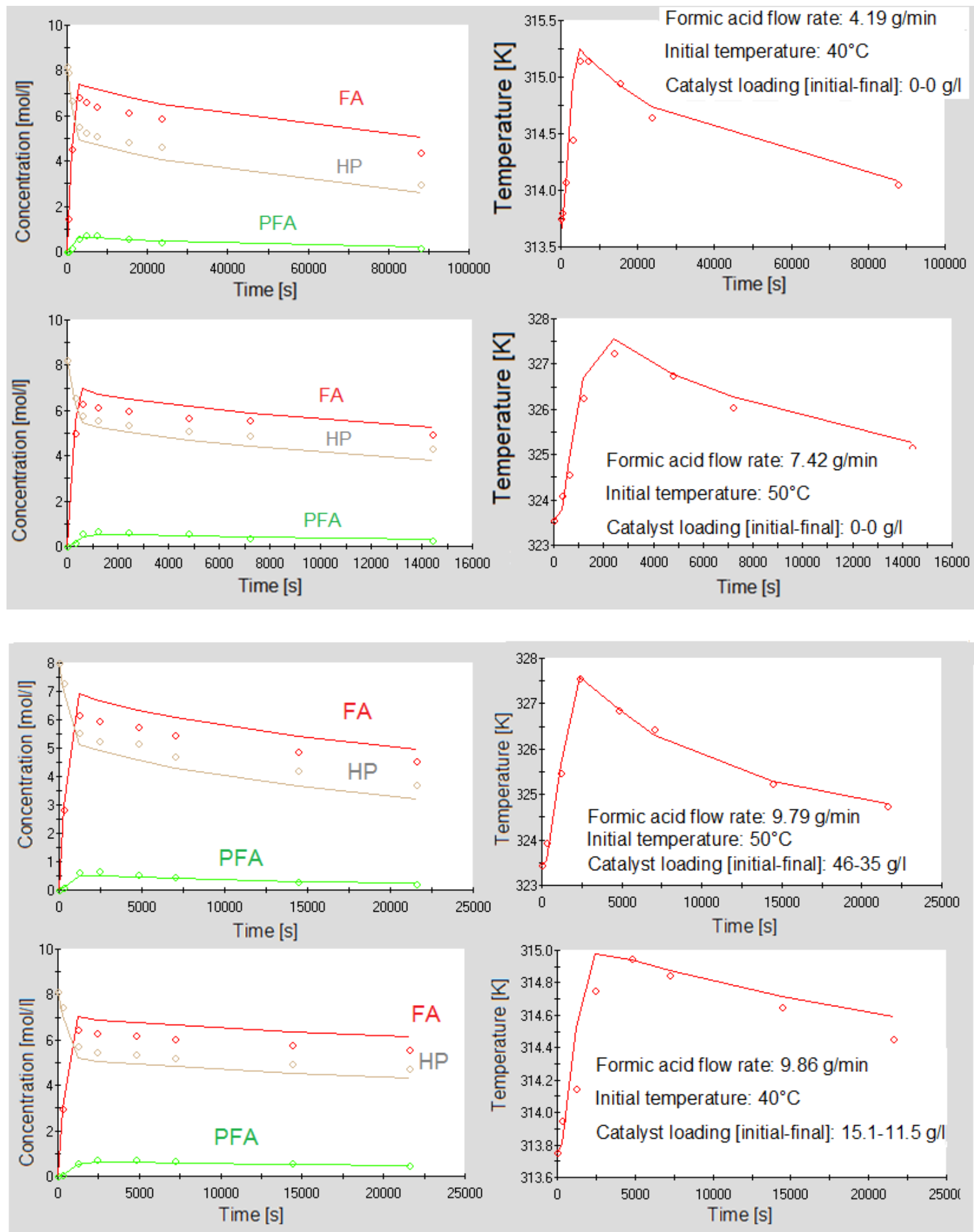

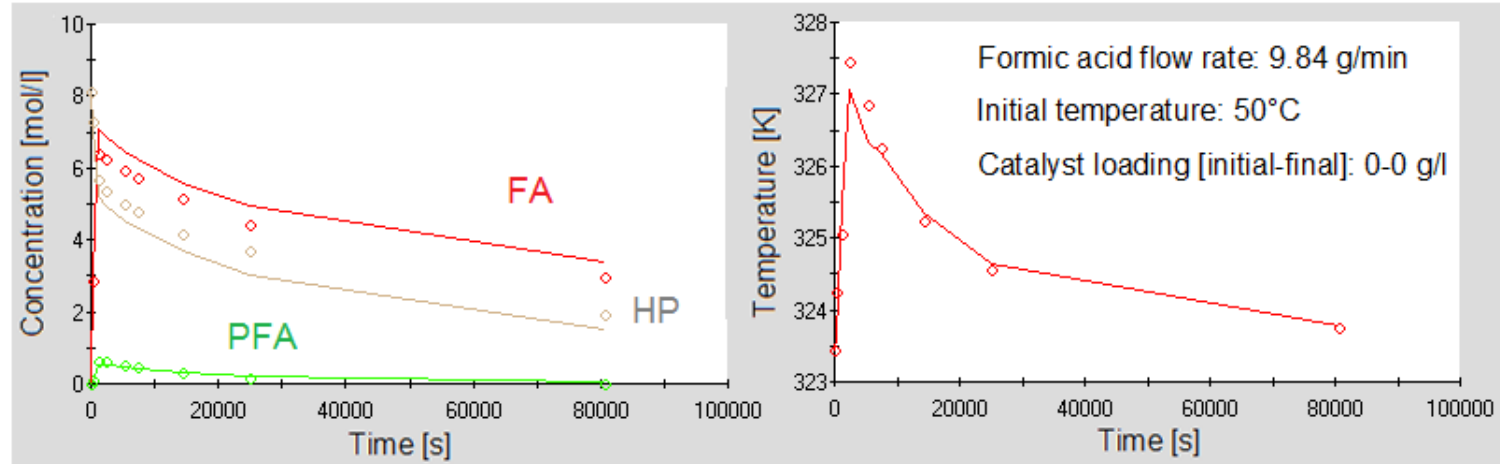

Figure 8. Fit of the model to the experiment (line corresponds to the model and points to experimental data).

Only the studies carried out by De Filippis et al. [12] and Sun et al. [13] can be used as comparison because the self-catalyzed effect of formic acid and the peroxyformic acid decomposition were included in their models. Table 5 displays the different value of the rate constants and activation energies at $318.15 \mathrm{~K}$.

Table 5. Comparison of kinetics and thermodynamic parameters for the formic acid perhydrolysis and peroxyformic acid decomposition

\begin{tabular}{|ccccc|}
\hline \multirow{2}{*}{ Sun et al. } & $\mathrm{k}_{\text {hom }}\left[\mathrm{I}^{2} \cdot \mathrm{mol}^{-2} \cdot \mathrm{s}^{-1}\right]$ & $\mathrm{Ea}[\mathrm{J} / \mathrm{mol}]$ & $\mathrm{k}_{\text {decomp. }}\left[\mathrm{s}^{-1}\right]$ & $\mathrm{Ea} \mathrm{J} / \mathrm{mol}$ \\
& $2.95 \cdot 10^{-4}$ & 75200 & $9.53 \cdot 10^{-5}$ & 95400 \\
\hline \multirow{2}{*}{ De Filippis et al. } & $\mathrm{k}_{\text {hom }}\left[\mathrm{l}^{2} \cdot \mathrm{mol}^{-2} \cdot \mathrm{s}^{-1}\right]$ & Ea $[\mathrm{J} / \mathrm{mol}]$ & $\mathrm{k}_{\text {decomp. }}\left[\mathrm{l} \cdot \mathrm{mol}^{-1} \cdot \mathrm{s}^{-1}\right]$ & $\mathrm{Ea} \mathrm{J} / \mathrm{mol}$ \\
& $9.26 \cdot 10^{-4}$ & 43522 & $7.66 \cdot 10^{-3}$ & 72624 \\
\hline \multirow{2}{*}{ Our study } & $\mathrm{k}_{\text {hom }}\left[\mathrm{I}^{2} \cdot \mathrm{mol}^{-2} \cdot \mathrm{s}^{-1}\right]$ & $\mathrm{Ea}[\mathrm{J} / \mathrm{mol}]$ & $\mathrm{k}_{\text {decomp. }}\left[\mathrm{s}^{-1}\right]$ & $\mathrm{Ea} \mathrm{J} / \mathrm{mol}$ \\
& $0.871 \cdot 10^{-4}$ & 20000 & $0.127 \cdot 10^{-3}$ & 95100 \\
\hline
\end{tabular}

Concerning the results for the decomposition, the estimated parameters are similar. However, concerning the synthesis of peroxyformic acid through the homogeneous pathway, the value of the activation energy obtained in this study is lower. This difference can be explained by the fact that the rate constant were 
lumped with the dissociation constant of formic acid (Eq. 6), and, by the fact that both authors have not considered isothermal condition for their modelling. 


\subsection{Safety assessment}

The other goal of this work is to determine the Maximum Temperature of the Synthesis Reaction (MTSR) and the adiabatic Time-to-Maximum Rate (TMRad). For the sake of simplicity, full accumulation will be assumed which is equivalent to consider that the reaction system is in batch reactor.

Figure 9 illustrates the well-known scenario of the cooling failure, which could lead to the thermal runaway. The thermal runaway is due to unwanted reaction such as decomposition occurring at temperature higher than MTSR.

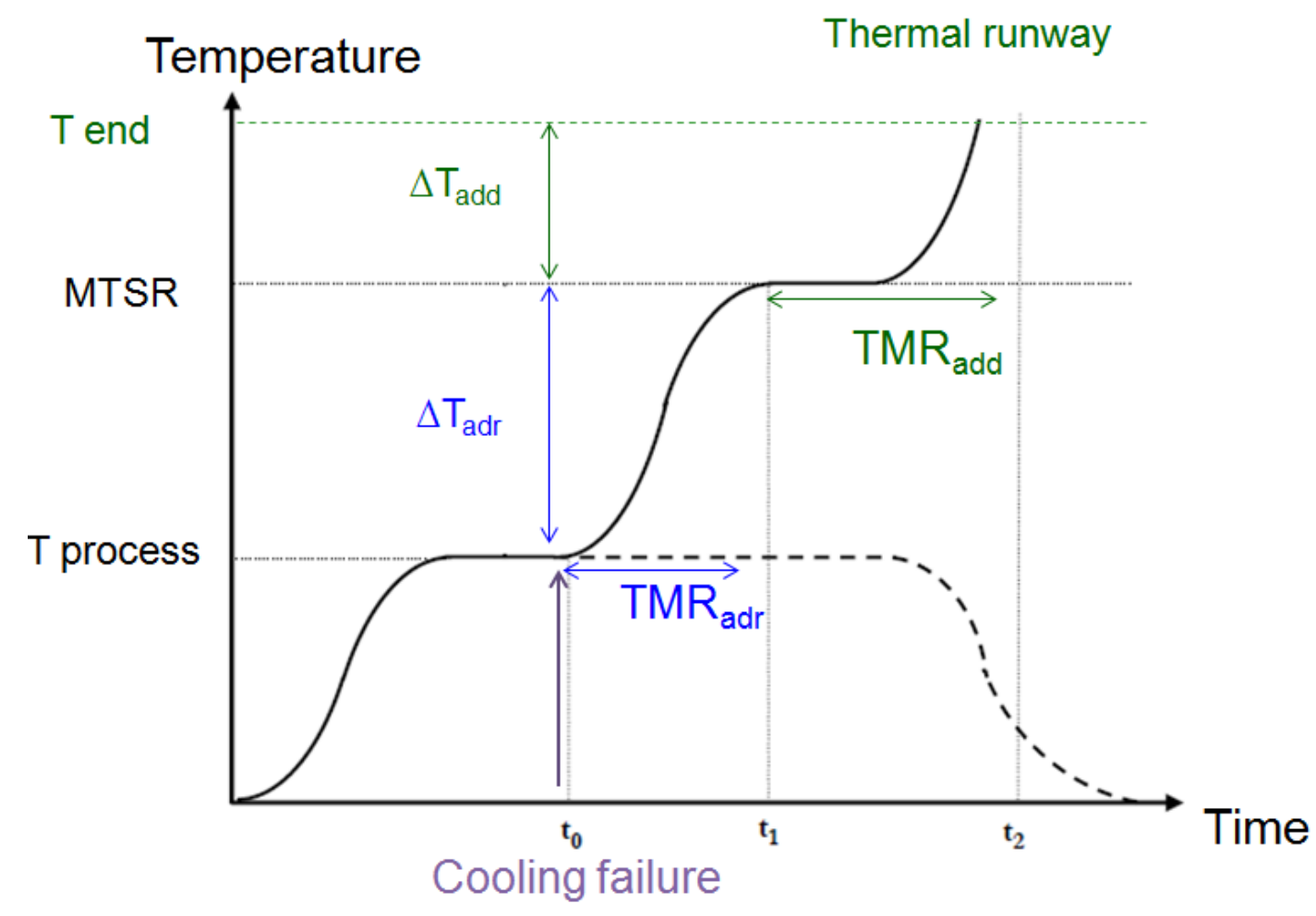

Figure 9. Scenario of cooling failure with thermal runaway.

where $\Delta T_{\text {adr }}$ stands for the adiabatic rise due to the synthesis reactions (formic acid perhydrolysis and peroxyformic acid decomposition), $\mathrm{TMR}_{\text {adr }}$ stands for the 
time to maximum rate from the beginning of the cooling failure to the MTSR, $\Delta T_{\text {add }}$ stands for the adiabatic rise due to the degradation reactions and $\mathrm{TMR}_{\text {add }}$ stands for the time to maximum rate from the MTSR. One should remember that the reactions occurring during the degradation phase are due to higher temperature. Such reactions can be studied in adiabatic reactor and we did not do it. In our case, we can estimate $\Delta \mathrm{T}_{\text {adr }}$ and $\mathrm{TMR}_{\mathrm{adr}}$. In the case of peroxyformic synthesis, perhydrolysis and decomposition reactions occur from the temperature process to the MTSR, at temperature higher than MTSR the degradation phase starts including different decomposition reactions more exothermic.

The adiabatic temperature rise $\Delta \mathrm{T}_{\text {adr }}$ is calculated from the equation

$$
\Delta T_{\text {adr }}=\frac{Q_{\text {reaction }}}{m_{r} \cdot \hat{C}_{P_{R}}^{\infty}}=\frac{\int_{0}^{\infty}\left(\Delta H_{\text {perh }} \cdot\left(-r_{\text {perh }}\right)+\Delta H_{\text {decomp }} \cdot\left(-r_{\text {decomp }}\right)\right) \cdot d t \cdot V_{R}}{m_{r} \cdot \hat{C}_{P_{R}}}
$$

A first approach to calculate the MTSR, the following assumptions were made:

- the enthalpy of the PFA decomposition was temperature independent within the range of $30-60^{\circ} \mathrm{C}$,

- the enthalpy of reaction (perhydrolysis) was negligible,

- an average value of the heat of capacity was used,

- complete conversion of hydrogen peroxide was assumed.

Thus, Eq. (31) becomes 


$$
\begin{aligned}
\Delta T_{\text {adr }} & =\frac{Q_{\text {reaction }}}{m_{r} \cdot \hat{C}_{P_{R}}}=\frac{\int_{0}^{\infty}\left(\Delta H_{\text {perh }} \cdot\left(-r_{\text {perh }}\right)+\Delta H_{\text {decomp }} \cdot\left(-r_{\text {decomp }}\right)\right) \cdot d t \cdot V_{R}}{m_{r} \cdot \hat{C}_{P_{R}}} \\
& \approx \frac{-\Delta H_{\text {decomp }} \cdot\left[H_{2} \mathrm{O}_{2}\right]_{0} \cdot X_{H_{2} O_{2}} \cdot V_{R}}{m_{r} \cdot \hat{C}_{P_{R}}}
\end{aligned}
$$

MTSR is equal to

$$
\mathrm{MTSR}=\mathrm{T}_{\text {process }}+\Delta \mathrm{T}_{\mathrm{adr}}
$$

The MTSR was evaluated for a process temperature at $30^{\circ} \mathrm{C}, 40^{\circ} \mathrm{C}$ and $60^{\circ} \mathrm{C}$.

Table 6. Adiabatic temperature rise

\begin{tabular}{|c|c|c|c|}
\hline Initial Temperature $[\mathrm{K}]$ & 303 & 313 & 323 \\
\hline$\overline{\hat{\mathrm{C}}}_{\mathrm{PR}}[\mathrm{J} / \mathrm{kg} / \mathrm{K}]$ & 2203 & 2199 & 2338 \\
\hline$\Delta \mathrm{T}_{\mathrm{ad}}[\mathrm{K}]$ & 745 & 755 & 708 \\
\hline $\mathrm{MTSR}[\mathrm{K}]$ & 1048 & 1068 & 1031 \\
\hline
\end{tabular}

For an initial temperature within the range $30-60^{\circ} \mathrm{C}$, the MTSR is higher than $727^{\circ} \mathrm{C}$ (Table 6), which is a high temperature. However, one should not forget that the calculation of MTSR is based on the fact that there is no evaporation of the reaction mixture and complete adiabatic condition. For this reason, one should take into account the Maximum Temperature for Technical reasons (MTT), which is the boiling point of water, i.e., $100^{\circ} \mathrm{C}$.

The TMRadr can be evaluated from

$$
\operatorname{TMR}_{\mathrm{adr}}\left(\mathrm{T}_{\mathrm{P}}\right)=\frac{\mathrm{m}_{\mathrm{R}} \cdot \hat{\mathrm{C}}_{\mathrm{PR}} \cdot \mathrm{R} \cdot \mathrm{T}_{\mathrm{P}}^{2}}{\mathrm{q}_{\mathrm{P}} \cdot \mathrm{E}_{\mathrm{a}}}
$$


Only the decomposition of peroxyformic acid will be considered here. Thus, energy activation in Eq. (34) is the decomposition one, i.e., $95.1 \mathrm{~kJ} / \mathrm{mol}$ and the energy released $\mathrm{q}_{\mathrm{p}}$ becomes

$\mathrm{q}_{\mathrm{P}}\left(\mathrm{T}_{\mathrm{P}}\right)=\mathrm{k}_{\text {decomp }}\left(\mathrm{T}_{\mathrm{P}}\right) \cdot[\mathrm{PFA}]_{0} \cdot\left(-\Delta \mathrm{H}_{\text {decomp }}\right)$

Because there is not peroxyformic acid at the beginning, the initial concentration of hydrogen peroxide concentration was used, i.e., $7 \mathrm{~mol} / \mathrm{l}$. The mass of the reaction system can be assumed to be $0.5 \mathrm{~kg}$.

Table 7. TMRadr

\begin{tabular}{|c|c|c|c|}
\hline Initial Temperature $[\mathrm{K}]$ & 303 & 313 & 323 \\
\hline$\overline{\hat{\mathrm{C}}}_{\mathrm{PR}}[\mathrm{J} / \mathrm{kg} / \mathrm{K}]$ & 2203 & 2199 & 2338 \\
\hline $\mathrm{k}_{\text {decomp }}\left[\mathrm{s}^{-1}\right]$ & $2.09 \mathrm{E}-05$ & $7.06 \mathrm{E}-05$ & $2.21 \mathrm{E}-04$ \\
\hline $\mathrm{q}_{\mathrm{P}}[\mathrm{J} / \mathrm{s}]$ & 33 & 110 & 345 \\
\hline $\mathrm{TMR}_{\text {adr }}[\mathrm{s}]$ & 268 & 85 & 31 \\
\hline
\end{tabular}

To get a TMRadr of 24 hours, the initial process temperature should be $262 \mathrm{~K}$.

The MTT and MTSR are higher than TMRadr leading to a criticacility of class 5 according to Stoessel [23]. In case of loss of control of synthesis reaction, the MTT will be reached and thus an evaporative cooling system should be set-up to avoid to trigger decomposition reaction of the degradation phase. From a security point of view, one should diminish the concentrations, work in continuous reactor. 


\section{CONCLUSIONS}

The goal of this paper was to develop a mathematical model including mass and energy balances in a semi-batch calorimetric reactor for formic acid perhydrolysis in the absence and presence of a solid acid catalyst. The validity of this model is correct for a water concentration range of $45-49 \mathrm{~mol} / \mathrm{l}$, a solid acid catalyst amount range of $0.0-10.6$ grams, a formic acid inlet molar ratio from 0.04 to 0.22 $\mathrm{mol} / \mathrm{min}$ and a temperature range $30-60^{\circ} \mathrm{C}$.

The enthalpy of peroxyformic acid decomposition was found to be equal to -217 $\mathrm{kJ} / \mathrm{mol}$, whereas the one for the synthesis was estimated to be very low, -4.54 $\mathrm{kJ} / \mathrm{mol}$. This estimation shows that the exothermicity of the system is mainly due to the decomposition step. Two different reaction pathways were identified for formic acid perhydrolysis, a homogeneous one with an activation energy estimated to $20 \mathrm{~kJ} / \mathrm{mol}$ and a heterogeneous one with an activation energy estimated to $1.7 \mathrm{~kJ} / \mathrm{mol}$. The activation energies of the decomposition and synthesis were estimated to $95.1 \mathrm{~kJ} / \mathrm{mol}$. The values of the kinetic parameters reveal that the synthesis reaction is fast and decomposition mechanism is promoted at higher temperatures.

A safety assessment was carried out showing that the criticality of this reaction is 5 according to Stoessel classification. The safety design should be focused on the pressure relief and using continuous system instead of batch one in case of 
industrial production. However, due to the criticality class of such system, it is safer to produce in-situ such chemicals. 


\section{NOTATION}

\begin{tabular}{|c|c|}
\hline A & heat transfer area $\left[\mathrm{m}^{2}\right]$ \\
\hline $\mathrm{C}_{\mathrm{P}}$ & constant-pressure heat capacity $[\mathrm{J} / \mathrm{K}]$ \\
\hline$\overline{\mathrm{C}}_{\mathrm{P}}$ & constant-pressure heat capacity per mol $[\mathrm{J} / \mathrm{mol} / \mathrm{K}]$ \\
\hline$\hat{\mathrm{C}}_{\mathrm{P}}$ & constant-pressure heat capacity per mass $[\mathrm{J} / \mathrm{kg} / \mathrm{K}]$ \\
\hline $\mathrm{Ea}$ & activation energy $\left[\mathrm{J} . \mathrm{mol}^{-1}\right]$ \\
\hline $\mathrm{H}$ & enthalpy $[\mathrm{J}]$ \\
\hline$\overline{\mathrm{H}}$ & molar enthalpy $[\mathrm{J} / \mathrm{mol}]$ \\
\hline$\Delta \mathrm{H}_{\mathrm{r}}^{\mathrm{o}}$ & standard reaction enthalpy $\left[\mathrm{kJ} \cdot \mathrm{mol}^{-1}\right]$ \\
\hline$\Delta \mathrm{H}_{\mathrm{v}}$ & heat of vaporisation [J/mol] \\
\hline $\mathrm{K}^{\mathrm{c}}$ & equilibrium constant, based on concentrations \\
\hline $\mathrm{K}^{\top}$ & thermodynamic equilibrium constant, based on activies \\
\hline $\mathrm{k}$ & rate constant $\left[1^{2} \cdot \mathrm{mol}^{-2} \cdot \mathrm{s}^{-1}\right]$ \\
\hline $\mathrm{k}_{\text {decomp }}$ & decomposition rate constant $\left[\mathrm{s}^{-1}\right]$ \\
\hline $\mathrm{m}$ & mass $[\mathrm{kg}]$ \\
\hline$\dot{n}$ & flow of the amount of substance $\left[\mathrm{mol} . \mathrm{s}^{-1}\right]$ \\
\hline $\mathrm{P}$ & pressure \\
\hline$Q_{f}$ & volumetric flow rate $[1 / \mathrm{s}]$ \\
\hline$\dot{\mathrm{Q}}_{\mathrm{c}}$ & electrical calibration $[\mathrm{W}]$ \\
\hline$\dot{\mathrm{Q}}$ & heat transfer rate $[\mathrm{W}]$ \\
\hline$\dot{\mathrm{Q}}_{\mathrm{ex}}$ & heat flux enchanged with the reactor jacket [W] \\
\hline$\dot{\mathrm{Q}}_{\text {loss }}$ & heat flux lost through the top of the reactor [W] \\
\hline $\mathrm{R}$ & gas constant $\left[\mathrm{J} \cdot \mathrm{K}^{-1} \cdot \mathrm{mol}^{-1}\right]$ \\
\hline$R^{2}$ & coefficient of explanation [\%] \\
\hline
\end{tabular}




$\begin{array}{ll}\mathrm{r}_{\mathrm{i}} & \left.\text { reaction rate [mol. } \mathrm{I}^{-1} \cdot \mathrm{s}^{-1}\right] \\ \mathrm{T} & \text { temperature } \\ \Delta \mathrm{T}_{\text {add }} & \text { adiabatic rise due to degradation reactions } \\ \Delta \mathrm{T}_{\text {adr }} & \text { adiabatic rise due to synthesis reactions } \\ \mathrm{U} & \text { internal energy [J] } \\ \mathrm{U} & \text { overall heat transfer coefficient }\left[\mathrm{W} \cdot \mathrm{m}^{-2} \cdot \mathrm{K}^{-1}\right] \\ \mathrm{V}_{\mathrm{D}} & \text { volume of reaction [l] } \\ \mathrm{V}_{0} & \text { initial volume [l] } \\ \dot{\mathrm{W}}_{\text {Shaft }} & \text { shaft work [W] } \\ \dot{\mathrm{W}}_{\text {Boundary }} & \text { boundary work }[\mathrm{W}] \\ \mathrm{X} & \text { conversion }\end{array}$

Greek letters

$\begin{array}{ll}v_{\mathrm{ij}} & \text { stoechiometric coefficient } \\ \rho & \text { mass density }[\mathrm{kg} /[] \\ \omega & \text { objective function }\end{array}$

Abreviations

FA formic acid

PFA peroxyformic acid

TMR time to maximum rate

MTSR maximum temperature of synthesis reaction

MTT maximum temperature for technical reasons 


\section{ACKNOWLEDGMENT}

The financial support from Academy of Finland and "Département Maîtrise des

Risques Industriels et Environnementaux" (INSA de Rouen) are gratefully acknowledged. The authors express their gratitude to Bruno Daronat and Dr. Alain Ledoux for their technical assistance. 


\section{REFERENCES}

[1] Goud, V. V.; Patwardhan, A. V.; Dinda, S.; Pradhan, N. C. Kinetics of Epoxidation of Jatropha Oil with Peroxyacetic and Peroxyformic Acid Catalysed by Acidic Ion Exchange Resin. Chem. Eng. Sci. 2007, 62, 4065-4076.

[2] Campanella, A.; Baltanás, M. A. Degradation of the Oxirane Ring of Epoxidized Vegetable Oils in a Liquid-Liquid-Solid Heterogeneous Reaction Rystem. Chem. Eng. Process. 2007, 46, 210-221.

[3] Lathi, P. S.; Mattiasson, B. Green Approach for the Preparation of Biodegradable Lubricant Base Stock from Epoxidized Vegetable Oil. Appl. Catal. B: Environ. 2007, 69, 207-212.

[4] Campanella, A.; Rustoy, E.; Baldessari, A.; Baltanás, M. A. Lubricants from Chemically Modified Vegetable Oils. Bioresource Technol. 2010, 101, 245-254.

[5] Santacesaria, E.; Tesser, R.; Di Serio, M.; Turco, R.; Russo, V.; Verde, D. A Biphasic Model Describing Soybean Oil Epoxidation with $\mathrm{H} 2 \mathrm{O} 2$ in a Fed-Batch Reactor. Chem. Eng. J. 2011, 173, 198-209.

[6] Phillips, B.; Starcher, P. S.; Ash, B. D. Preparation of Aliphatic Peroxyacids. J. Org. Chem. 1958, 23, 1823-1826.

[7] Cantieni R. Photochemical Peroxide Formation. VII. Oxidation of Acetic, Propionic, Butyric and Isovaleric Acids by Means of Molecular Oxygen in Ultraviolet Light. Zeitschrift fuer Wissenschaftliche Photographie, Photophysik und Photochemie. 1937, 36, 90-95.

[8] Noyori, R. Pursuing Practical Elegance in Chemical Synthesis. Chem. Commun. 2005, 14, 1807-1811. 
[9] Leveneur, S.; Murzin, D. Y.; Salmi, T.; Mikkola, J.-P.; Kumar, N.; Eränen, K.; Estel, L. Synthesis of Peroxypropionic Acid from Propionic Acid and Hydrogen Peroxide over Heterogeneous Catalysts. Chem. Eng. J. 2009, 147, 323-329.

[10] D’Ans, J.; Frey, W.; Untersuchungen über die Bildung von Persäuren aus organischen Säuren und Hydroperoxyd, Z. anorg. Chem. 1914, 84, 145-64.

[11] Rubio, M.; Ramírez-Galicia, G.; López-Nava, L. J. Mechanism formation of peracids. J. Mol. Struc.-THEOCHEM 2005, 726, 261-269.

[12] Filippis, P. D.; Scarsella, M.; Verdone, N. Peroxyformic Acid Formation: A Kinetic Study. Ind. Eng. Chem. Res. 2008, 48, 1372-1375.

[13] Sun, X.; Zhao, X.; Du, W.; Liu, D. Kinetics of Formic Acid-autocatalyzed Preparation of Performic Acid in Aqueous Phase. Chinese J. Chem. Eng. 2011, 19, 964-971.

[14] Greenspan, F. P.; MacKellar, D. G. Analysis of Aliphatic Per Acids. Anal. Chem. 1948, 20, 1061-1063.

[15] Leveneur, S.; Salmi, T.; Murzin, D. Y.; Estel, L.; Warna, J.; Musakka, N. Kinetic Study and Modeling of Peroxypropionic Acid Synthesis from Propionic Acid and Hydrogen Peroxide Using Homogeneous Catalysts. Ind. Eng. Chem. Res. 2008, 47, 656-664.

[16] Leveneur, S.; Wärnå, J.; Salmi, T.; Murzin, D. Yu.; Estel, L.; Interaction of Intrinsic Kinetics and Internal Mass Transfer in Porous lon-exchange Catalysts: Green Synthesis of Peroxycarboxylic Acids. Chem. Eng. Sci. 2009, 64, 41014114. 
[17] Leveneur, S.; Salmi, T.; Musakka, N.; Wärnå, J. Kinetic Study of Decomposition of Peroxypropionic Acid in Liquid Phase Through Direct Analysis of Decomposition Products in Gas Phase. Chem. Eng. Sci. 2007, 62, 5007-5012. [18] Musakka, N.; Salmi, T.; Wärnå, J.; Ahlkvist, J.; Piironen, M. Modelling of Organic Liquid-Phase Decomposition Reactions Through Gas-Phase Product Analysis: Model Systems and Peracetic Acid. Chem. Eng. SciS 2006, 61, 69186928.

[18] Musante R.L.; Grau R.J.; Baltanas M.A. Kinetic of Liquid-Phase Reactions Catalyzed by Acidic Resins: the Formation of Peracetic Acid for Vegetable Oil Epoxidation. Appl. Catal. A 2000, 197, 165-173.

[19] Harned, H.S.; Embree N.D. The Ionization Constant of Formic Acid from 0 to 60 C. J. Am. Chem. Soc., 1934, 56(5), 1042-1044.

[20] Milewska, A.; Molga, E. Safety aspects in Modelling and Operating of Batch and Semibatch Stirred Tank Chemical Reactors. Chem. Eng. Res. Des. 2010, 88, 304-319.

[21] Ubrich O.; Srinivasan B.; Lerena P.; Bonvin D.; Stoessel F. The Use of Calorimetry for On-Line Optimisation of Isothermal Semi-Batch Reactors. Chem. Eng. Sci. 2001, 56, 5147-5156.

[22] Haario, H. MODEST-User's Guide; Profmath Oy: Helsinki, 2001.

[23] Stoessel F. Thermal Safety of Chemical Processes: Risk Assessment and Process Design; Wiley-VCH Verlag GmbH, 2008. 